\title{
Production Rate Control policy for Stochastic Remanufacturing Systems
}

\author{
A. Gharbi, R. Pellerin, and J. Sadr \\ University of Quebec, École de Technologie Supérieure \\ Production Systems Design and Control Laboratory \\ Department of automated production engineering \\ ali.gharbi@etsmtl.ca, robert.pellerin@etsmtl.ca, and javad.sadr@polymtl.ca
}

\begin{abstract}
We consider the control of a manufacturing system executing single product remanufacturing operations in a close-loop system. In this paper, the remanufacturing resources respond to planned demand executed at the end of the expected life of each individual equipment and unplanned demand triggered by a major equipment failure. Remanufacturing operations for planned demands can be executed at different rates which referred to different component replacement and repair strategies. The system objective is to define the remanufacturing rate as a function of the serviceable equipment inventory level that minimizes the repair and inventory/shortage cost over an infinite horizon. The proposed policy, called multiple hedging point policy (MHPP), is described by two thresholds related to two accelerated repair rates. To determine the parameters of the control policy, and hence, to achieve a close approximation of the optimal repair policy, an experimental approach based on design of experiment, simulation modeling and response surface methodology is used. Our results show that the optimal cost incurred under the developed control policy is lower than that incurred under the classical hedging point policy (HPP).
\end{abstract}

\section{Keyword}

Remanufacturing, Repair, Overhaul, Maintenance, Control Policy, Simulation, Experimental Design, Response Surface Methodology. 


\section{Introduction}

Over the last decade, equipment driven organizations such as airlines companies and armed forces have been forced to become more and more flexible and efficient within existing budgets, and without compromising their operations. Those firms have also faced continuous pressures to become more environmentally responsible. In that context, many of these firms have implemented a material recovery system in order to increase their equipment product life through remanufacturing activities [1]. Remanufacturing, also referred to major overhaul, is here defined as the process in which worn-out equipments are restored to like-new condition at a lower cost than new products [2]. Remanufacturing systems offer potential advantages, including increased profitability through reduced material requirements, reduced acquisition cost, and improved market share based on environmental image [1].

Organizations involved in product remanufacturing can perform a wide range of repair tasks varying from minor repairs to complex technical upgrades programs [3]. In contrast to manufacturing operations, remanufacturing tasks are subject to a great deal of variability and uncertainty due to the unique condition of the items being repaired [3,4]. A typical remanufacturing task starts with a disassembly activity and an inspection phase where the production content is defined. The next step, the most important in terms of workload, includes the replacement and/or repair of a large number of components. At the same time, the main structure of the equipment can be overhauled and modified to accept new components and the repaired ones. The remanufacturing process then ends with the assembly and a final inspection.

Researchers have proposed a number of model addressing different issues related to product remanufacturing operations, including supply chain planning and management [1,5], inventory control [6,7], and operations scheduling [4,8,9]. To this point, the execution control of this unique type of operations has not been considered. The difficulty of controlling remanufacturing operations resides in the variable nature of each operation. The amount of work depends on the specific condition of each component being repaired and on the selected repair process. For each component, managers or technicians must decide on either repairing or replacing the failed component. While repairing a component usually cost less than replacing it, it does however take more time. When serviceable equipment inventory exceeds the actual demand or service level, remanufacturing 
organizations will typically choose to repair most of the components in order to reduce costs. When the number of serviceable equipments moves near the required service level, it is possible to accelerate the remanufacturing process by replacing components and subassembly instead of repairing them. While more costly, this accelerated process allows to quickly add more serviceable equipment to stock and therefore reducing the risk of not meeting the required service level. Between the repair and the full replacement remanufacturing control policies, it is possible to adopt an intermediate repair rate which consists of replacing only critical parts and repairing all other components. In defense organizations, this type of intermediate remanufacturing process is formalized and called Inspect and Repair Program [4]. It is important to note that when the number of serviceable equipment is insufficient, the operating firm engages significant costs by having to cancel operations or by renting equipments.

The purpose of this paper is to find a suboptimal solution for the remanufacturing control problem of one product subject to uncertain demand. The proposed repair rate control policy takes advantage of the possibility of executing remanufacturing tasks at different repair rate with the objective of minimizing total incurred costs. Before presenting the proposed approach, we present the remanufacturing problem and the related repair rate control policy in Section 2. In Section 3, the description of resolution approach is presented. The description of the model, based on discrete and continuous simulation, is presented in Section 4. Section 5 outlines the experimental design and response surface methodology. Results obtained in the previous sections are thereafter used to compare the proposed control policy with the classic hedging point policy in section 6 . The paper is concluded in Section 7.

\section{Problem statement}

We consider a close-loop remanufacturing system repairing a single equipment type with constant demand. The system is said to be close-loop since the operating firm controls both serviceable and non-serviceable stocks. Equipment disposal is not allowed and the equipment fleet, which corresponds to the total number of serviceable and non-serviceable equipments, remains constant. In this paper, the remanufacturing resources respond to two types of demand: planned demand executed at the end of the expected life of each individual equipment and unplanned demand triggered by a major equipment failure. Unplanned demands are here described by a stochastic variable. Major equipment repairs 
are processed in priority in order to put the equipment back in service as quickly as possible. Remanufacturing operations for planned demands can be executed at different rates. The system objective is to define the remanufacturing rate as a function of the serviceable equipment inventory level that minimizes the remanufacturing and inventory/shortage cost over an infinite horizon. The structure of the remanufacturing system under study is presented in Figure 1.

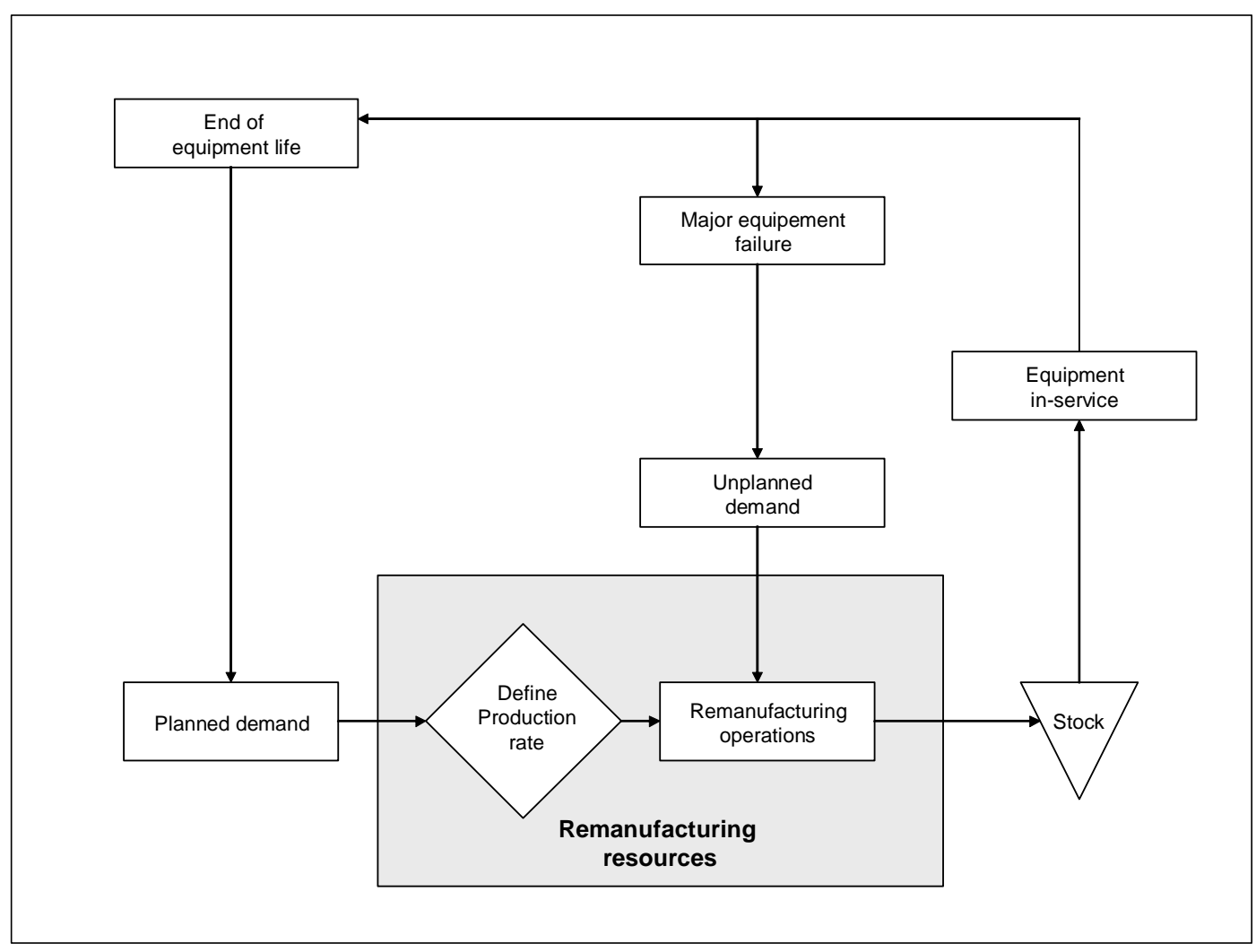

Figure 1. Structure of the remanufacturing system under study

The following notations will be used to describe the proposed control model:

$x(\mathrm{t})$ equipment surplus at time t: a positive value of $x(\mathrm{t})$ represents inventory, while a negative value represents backlog;

$u(\mathrm{t}) \quad$ control remanufacturing rate at time $\mathrm{t}$;

SL service level (i.e. the number of serviceable equipment required to support operations of the organization);

d demand rate; 
$\mathrm{c}^{-} \quad$ cost to be paid per equipment per unit time for failing to meet the service level;

$\mathrm{c}^{+} \quad$ cost to be paid per equipment per unit time for keeping inventory at a higher level than the service level;

$u_{1} \quad$ minimum repair rate (repair policy);

$u_{2} \quad$ intermediate repair rate (inspect and repair policy);

$u_{3} \quad$ maximum repair rate (replace policy);

$\mathrm{c}_{1} \quad$ cost per unit time when remanufacturing at the minimum rate;

$\mathrm{c}_{2} \quad$ cost per unit time when remanufacturing at the intermediate rate;

$c_{3} \quad$ cost per unit time when remanufacturing at the maximum rate;

$\lambda_{12}$ unplanned demand arrival rate;

$\lambda_{21} \quad$ unplanned demand processing rate;

$J(x, \alpha)$ long run average cost function; and

$\alpha \quad$ reparation mode when the system is on functional mode.

The system capacity is initially designed to produce at the expected demand rate $\left(u_{1}=d\right)$. As unplanned demand occurs, the remanufacturing resources are pre-empted until this demand is satisfied. Planned demands are therefore not satisfied during that period and the number of serviceable equipment $x(\mathrm{t})$ decreases. The managers of the remanufacturing system have the possibility of executing the planned demand at three different rates $\left(u_{1}, u_{2}\right.$, $u_{3}$ ) where $u_{1}<u_{2}<u_{3}$. Remanufacturing cost is rate related and increases as the repair rate is accelerated $\left(\mathrm{c}_{1}<\mathrm{c}_{2}<\mathrm{c}_{3}\right)$.

The inventory/backlog level of the remanufacturing system, $x(\mathrm{t})$, evolves according to the following differential equation:

$$
\dot{x}(t)=u_{\alpha}(x(t))-d, x(0)=x
$$

where, $x$ is the initial stock levels and $u_{\alpha}(x(t))$ is the repair rate control in mode $\alpha$.

The repair rate takes its value on a convex set $\Omega_{\alpha}$ in the closed interval $\left[0, \hat{u}_{\alpha}\right]$ where $\hat{u}_{\alpha}$ represents the maximum repair rate allowed by the capacity constraints of the manufacturing system when it is in mode $\alpha$. The state of remanufacturing system can be 
classified as "producing planned demand", denoted by 1, or "producing unplanned demand", denoted by 2 . This process could be modeled as a continuous time Markov chain when the transition from state to another is constant. The irreducible continuous time Markovian two-state transition process of producing planned demand and producing unplanned demand is shown in Figure 2.

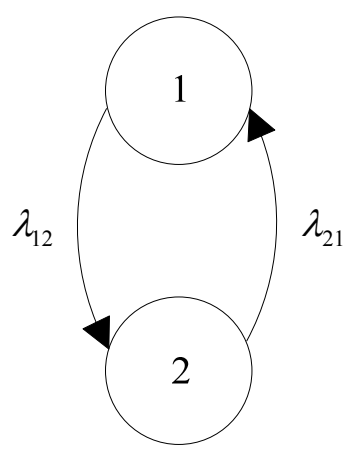

Figure 2. Two-sate Markovian representation of planned and unplanned demand.

This problem has many similarities with the production control problem of one product manufactured by one unreliable machine having two states (up and down). Akella and Kumar [10] found an exact solution to that problem. Bielecky and Kumar [11] solved the same problem using an approach that considers the long run average expected inventory/shortage cost. Sharifnia [12] solved the same problem considering multiple machine states. The objective in this latter work was to find the optimum production rate $u_{\alpha}$, for each machine state $\alpha$ and surplus level $x(\mathrm{t})$, so as to minimize the average surplus cost per unit time presented in below:

$$
J^{*}=\lim _{T \rightarrow \infty} \frac{1}{T} \mathrm{E}\left[\int_{0}^{T} g(x) d t \mid\left(x_{0}, \alpha_{0}\right)\right]
$$

Where $\mathrm{E}\left[\cdot \mid x_{0}, \alpha_{0}\right]$ is the expectation operator conditional on initial condition, $g(x)=c^{+} x^{+}(t)+c^{-} x^{-}(t)$, and $x^{+}=\max (0, x)$ and $x^{-}=\max (0,-x)$ are respectively the positive and negative part of the inventory/backlog surplus at time $t$.

The optimal solution of the control problem considering a cost function as described in (2) has never been found because of the complexity of stochastic HJB (Hamilton-JacobiBellman) coupled equations. To simplify the analytical calculation, a near optimal hedging point policy is considered. In this paper, the control policy is obtained by minimizing equation (2) as inspired from the multiple hedging point policy (MHPP) proposed in [12]. Such policy suggests that when the machine is up, one should produce at the maximum 
possible rate $\left(u_{\alpha}\right)$ when inventory level is less than a threshold $\left(z_{\alpha}\right)$, production should be set at the demand rate if the inventory level is exactly equal to the threshold, and no production is required if the inventory level exceeds the threshold.

Using the same structure of the MHPP model and according to the remanufacturing system described earlier, the cost of maintaining the inventory/shortage $x(t)$ for one time unit, denoted $g(x)$, takes the following form:

$$
g(x)=c^{+} x^{+}(t)+c^{-} x^{-}(t)+\sum_{\alpha=1}^{3} c_{\alpha} \pi_{\alpha} u_{\alpha}
$$

where in (3), $\pi_{\alpha}$ represents stationary probability of remanufacturing system state (i.e. $\pi_{\alpha}$ gives the percentage of the time for which the system produce at rate $u_{\alpha}$ in long run).

The optimal solution of this problem is therefore determined by minimizing the total cost of the remanufacturing processing rate and serviceable equipment inventory/backlog. Our proposed sub-optimal control policy is characterized by the pair of thresholds $\left(z_{1}, z_{2}\right)$ where $\left(z_{2}<z_{1}\right)$. A problem with cost function similar to (3) (penalty on repair rate) with minimizing discounted cost function has been shown numerically in Kenné et al [19] to be a multiple hedging points levels. Based on [12] and [2003], the repair rate control policy is proposed as follow:

$$
u(x)=\left\{\begin{array}{ccc}
u_{1} & \text { if } & x(t)=z_{1} \\
u_{2} & \text { if } & z_{2}<x(t)<z_{1} \\
u_{3} & \text { if } & x(t)<z_{2}
\end{array}\right.
$$

Consequently, the remanufacturing rate is set at the expected demand rate $\left(u_{1}=d\right)$ when $x(\mathrm{t})$ is at hedging point level $z_{1}$. As $x(\mathrm{t})$ drops below $z_{1}$, the remanufacturing process is accelerated at rate $u_{2}$. If $x(\mathrm{t})$ drops below $z_{2}$, the remanufacturing process is further accelerated at rate $u_{3}$ to prevent the inventory level to decrease under the service level SL.

\section{Resolution approach}

In the sphere of control theory, results from traditional production and maintenance planning methods are not sufficient to reach a comfortable level of desired performances. Optimal solutions are often difficult to calculate or obtained under strict conditions which limit the use for real cases. To improve these methods, we propose to combine the descriptive capacities of conventional simulation models with analytical models, 
experimental design, and response surface methodology techniques (see $[13,14,15])$. A synoptic scheme of the resolution approach is depicted in figure 2.

The structure of the proposed approach consists of the following sequential steps:

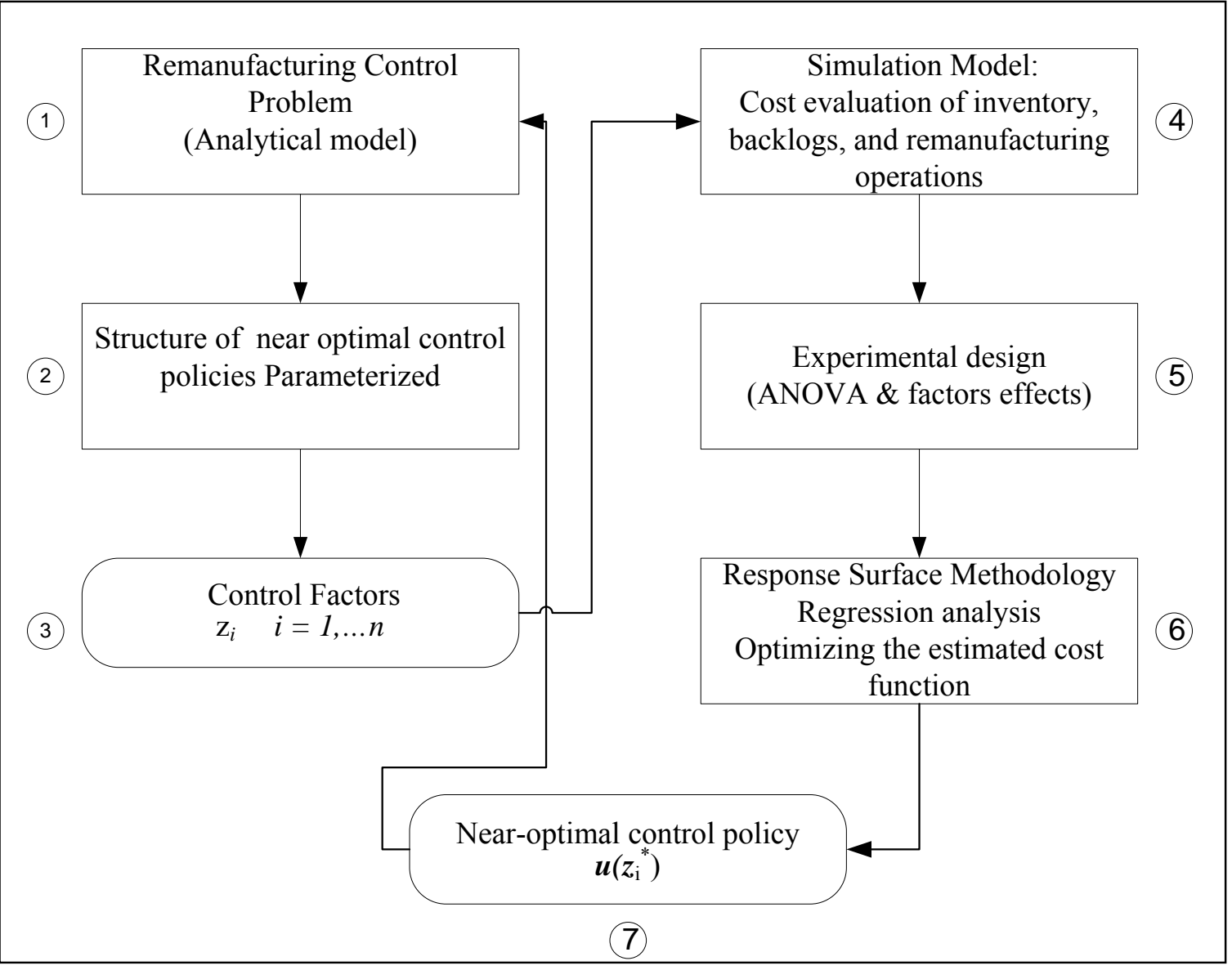

Figure 2. Proposed resolution approach

1. The Control problem statement of the remanufacturing system, as described in section 2, consists of the representation of the repair execution problem of the remanufacturing system through a stochastic optimal control model based on control theory. Hence, the problem of the optimal flow control for the remanufacturing system considered is described in this first step, which contains a specification of the objective of the study. That objective is to find the control variables $\left(\boldsymbol{u}_{i}\right)$ called the repair rates in order to improve the related output (i.e., the incurred cost). 
2. The Structure of near optimal control policy (3) is obtained, based on the work of Akella and Kumar [10], Bielecky and Kumar [11] and Sharifnia [12].

3. The Control factors $z_{i}, i=1, \ldots . n$ for repair planning of the remanufacturing system, describe the control policy obtained.

4. The Simulation model uses the near optimal control policy defined in the previous step as input for conducting experiments in order to evaluate the performances of the remanufacturing system. Hence, for given values of the control factors, the cost incurred is obtained from the simulation model presented in section 4.

5. The Experimental design approach defines how the control factors can be varied in order to determine the effects of the main factors and their interactions (i.e., analysis of variance or ANOVA) on the cost through a minimal set of simulation experiments.

6. The Response surface methodology is then used to obtain the relationship between the incurred cost and significant main factors and interactions given in the previous step. The obtained regression model is then optimized in order to determine best values of factors called here $z_{i}^{*}$ for repair.

7. The Near-optimal control policy $\mathbf{u}\left(\mathbf{z}_{j}^{*}\right)$ is then an improved hedging point policy to be applied to the remanufacturing system. The application of the proposed control approach gives the repair rates described by equations (3) for best values of factors $\mathrm{z}_{i}^{*}$.

The simulation model used in our approach is further described in the next section.

\section{Simulation model}

A simulation model that combines discrete-continuous changes describing the dynamics of the system presented in figure 1 was developed using the Visual SLAM language [16]. This model consists of several networks and user routines, each of which describes a specific task in the system (i.e., demand generation, control policy, states of the system, inventory control..., etc.). The diagram of the simulation model is shown in Figure 4 with the following block descriptions: 


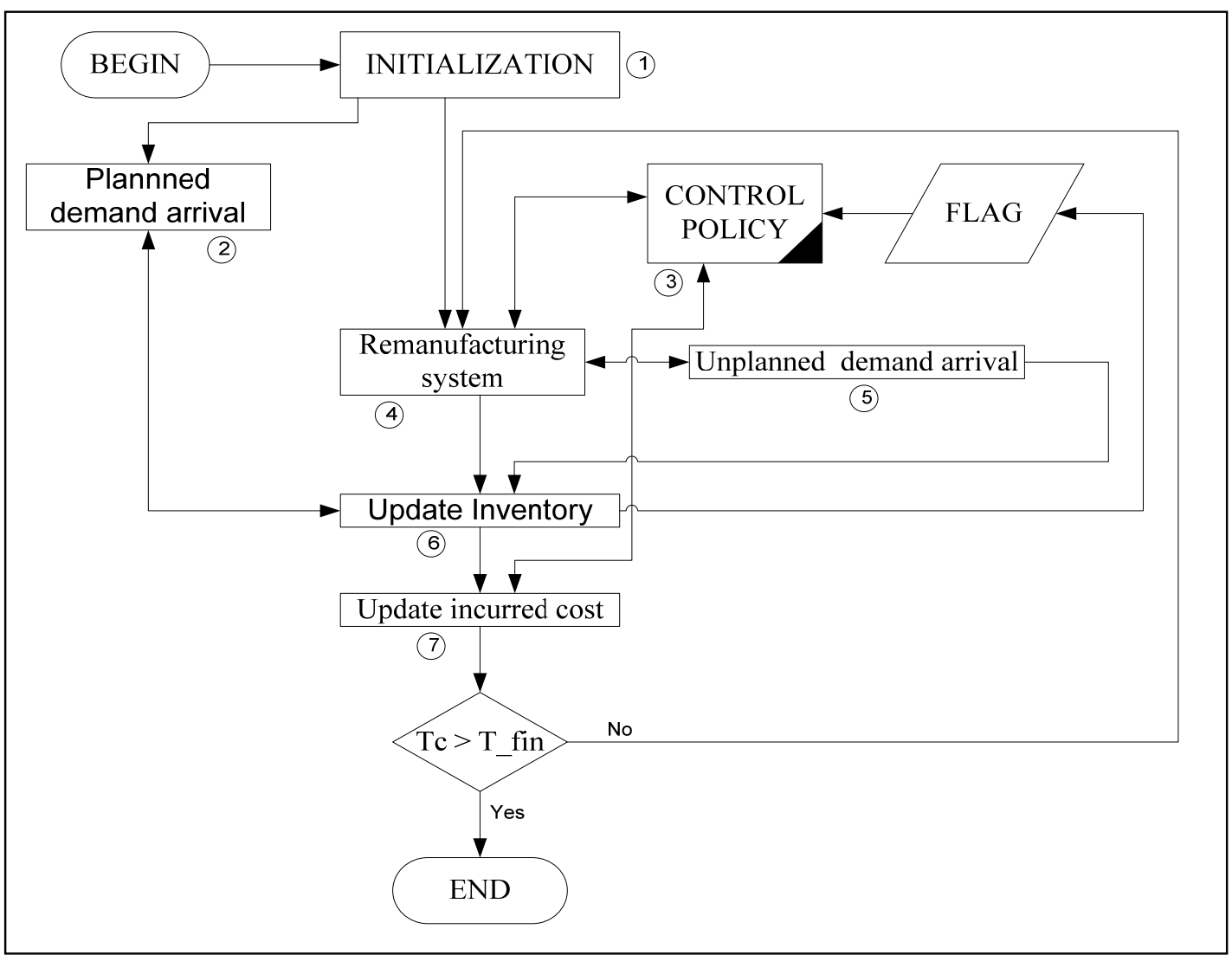

Figure 4. Diagram of simulation model

1. The INITIALIZATION block initializes the variables (current surplus, repair rates, incurred cost,...etc)

2. The PLANNED DEMAND ARRIVAL block performs the arrival of a planned demand for equipments to be overhauled at each $1 / \mathrm{d}$ unit of time. Verification is then performed on the inventory value of equipments surplus, and the inventory or the backlog level is updated.

3. The CONTROL POLICY segment block is defined in the previous section (see equation (3) for the system repair rates). The control policy is defined by the output of the FLAG block. This block is used to permanently verify the variation in the surplus level $x(t)$. If $x(t)>z_{1}$, then the repair rate is set to a zero value; otherwise the repair rate is either set to the demand rate $\left(u_{1}=\mathrm{d}\right)$ if $x(t)=z_{1}$, to the intermediate repair rate $\boldsymbol{u}_{2}$ if $z_{2} \leq x(t)<z_{1}$, or to the maximum repair rate $\boldsymbol{u}_{3}$ if $x(t)<z_{2}$.

4. The REMANUFACTURING SYSTEM block performs the remanufacturing activities of equipments according the repair rate as set by the control policy. 
5. The UNPLANNED DEMAND ARRIVAL block performs two functions: it defines the time between unplanned demand arrival $\left(\lambda_{12}^{-1}\right)$, and time to treat this unplanned demand $\left(\lambda_{21}^{-1}\right)$, using probability distributions. Recall that when an unplanned demand arrives, the remanufacturing resources are pre-empted until this demand is satisfied. Planned demands are therefore not satisfied during that period.

6. The UPDATE INVENTORY block traces the variation of the surplus level as equipment get remanufactured or as demand arrival occurs (i.e. remanufactured equipments either increase surplus if there is no backorder or it satisfies the cumulative demand, and hence decreases the backorder level). In figure 5, we present the equipment surplus trajectory for remanufacturing system defined by the following numerical values: $d=20 ; u_{2}=25 ; u_{3}=40 ; \lambda_{12}=4 ; \lambda_{21}=10 ; \mathrm{z}_{1}=15.02, \mathrm{z}_{2}=4.14$ and $\mathrm{SL}=0$. Note that $\lambda_{12}^{-1}$ and $\lambda_{21}^{-1}$ follow exponential distributions. It is interesting to note that: (i) the surplus level increases to $z_{1}$ and remains at this value; (ii) the surplus level decreases during unplanned demand treatment period; (iii) the surplus level of equipments depends on remanufacturing rates $\left(u_{1}, u_{2}\right.$ or $\left.u_{3}\right)$ and unplanned demand characteristics $\left(\lambda_{12}\right.$ and $\left.\lambda_{21}\right)$.

7. The UPDATES INCURRED COST block calculates in a real time the costs of, inventory, backlogs and repair which depend on the remanufacturing rates $\left(u_{1}, u_{2}\right.$ or $\left.u_{3}\right)$.

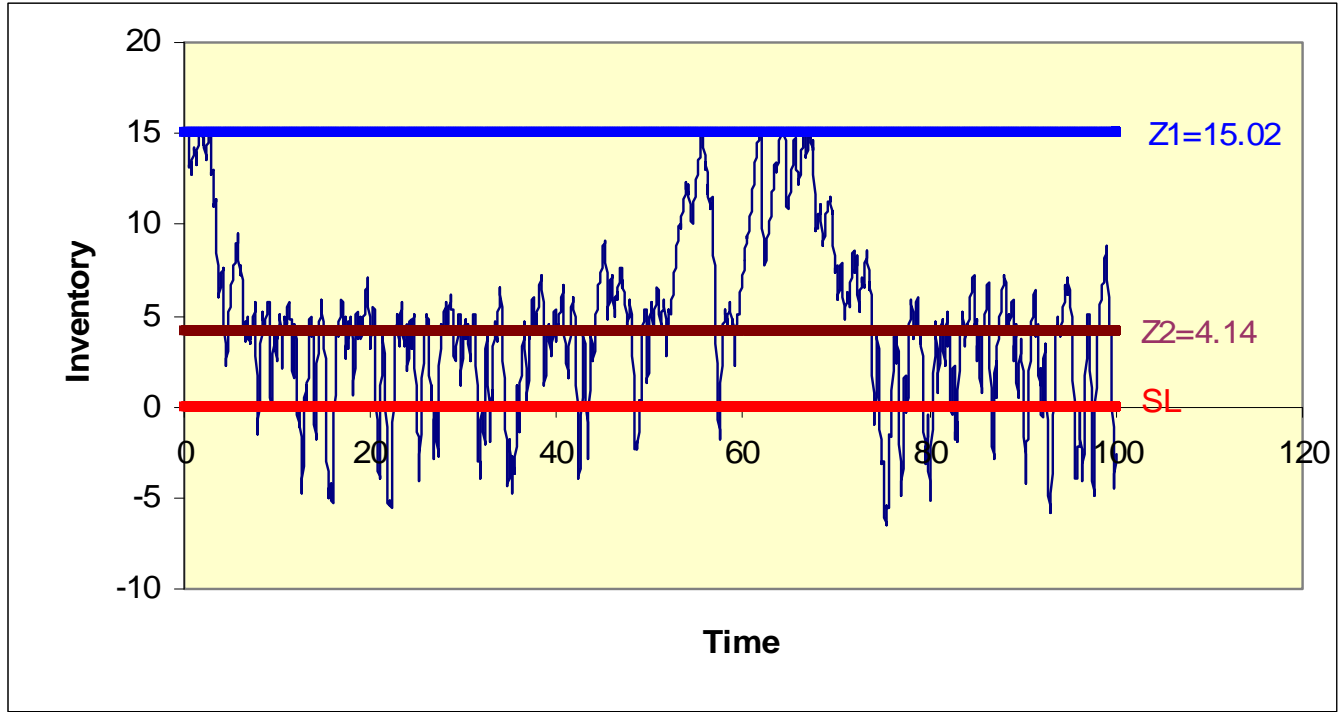

Figure 5. Equipments surplus trajectory $\left(\mathrm{z}_{1}=15.02\right.$ and $\mathrm{z}_{2}=4.14$ and $\left.\mathrm{SL}=0\right)$ 


\section{Experimental design and response surface methodology}

In this study, we collect and analyze steady state cost data. Given that an optimal solution of the stochastic control problem described in section 2 exists and the convexity property of the cost function, we need three levels for each factor $z_{1}$ and $z_{2}$ to obtain a convex estimated cost function. These observations give rise to a complete $3^{2}$ experimental design [17].

\subsection{Numerical example}

The following numerical values were used as presented previously: $d=\boldsymbol{u}_{1}=20 ; \boldsymbol{u}_{2}=25$; $\boldsymbol{u}_{3}=40 ; \lambda_{12}=4 ; \lambda_{21}=10 ; \mathrm{c}^{+}=10 ; \mathrm{c}^{-}=100 ; c_{1}=20 ; c_{2}=40 ; c_{3}=100$. We also define a new variable A $\left(0 \leq \mathrm{A} \leq 1\right.$ and $\left.\mathbf{z}_{2}=\boldsymbol{A}^{*} \mathbf{z}_{1}\right)$ such as to ensure that the constraint $\left(\mathbf{z}_{2}<\mathbf{z}_{1}\right)$ is respected. Based on off-line simulation runs, where the minimum and the maximum values of the factors were observed, the independent variable levels were chosen as presented in Table 1 .

\begin{tabular}{|c|c|c|c|}
\hline Factor & Low Level & Center & High Level \\
\hline $\mathbf{z}_{\mathbf{1}}$ & 1 & 10.5 & 20 \\
\hline A & 0.05 & 0.5 & 0.95 \\
\hline
\end{tabular}

Table 1. Level of independent variables

Two replications were conducted for each combination of the factors, and therefore, 18 $\left(3^{2} x 2\right)$ simulation runs were made. To unsure that the steady-state of the cost is achieved the simulation model is run during 100,000 time units for each replication. To reduce the number of replications, we used a variance reduction technique called common random numbers [18]. We conducted some preliminary simulation experiments using 2 replications, and noticed that the variability allows the effects to be distinguished.

\subsection{Result Analysis}

The statistical analysis of the simulation data consists of the multifactor analysis of variance (ANOVA). This is done using a statistical software application (STATGRAPHICS) to provide the effects of the two independent variables $\left(z_{1}\right.$, and A) on the dependant variable (incurred cost). The ANOVA table corresponding to the generated 
data is illustrated in Table 2. All p-values are less than 5\%. Consequently, we conclude that the main factors $z_{1}$, and $A$, their quadratic effects, as well as their interactions are significant at the 0.05 level. The R-squared value of 0.9736 from the ANOVA table states that about $97.4 \%$ of the total variability is explained by the model [17].

\begin{tabular}{|c|c|c|c|c|c|}
\hline & Sum of squares & d.f. & Mean square & F-ratio & P-value \\
\hline $\mathbf{z}_{\mathbf{1}}$ & 38761.7 & 1 & 38761.7 & 129.18 & 0.0000 \\
\hline $\boldsymbol{A}$ & 40436.0 & 1 & 40436.0 & 134.76 & 0.0000 \\
\hline $\mathbf{z}_{\mathbf{1}}{ }^{\mathbf{2}}$ & 25505.6 & 1 & 25505.6 & 85.00 & 0.0000 \\
\hline $\mathbf{z}_{\mathbf{1}} \mathbf{A}$ & 7930.37 & 1 & 7930.37 & 26.43 & 0.0003 \\
\hline $\boldsymbol{A}^{2}$ & 94827.2 & 1 & 94827.2 & 30.43 & 0.0002 \\
\hline $\mathbf{b l o c k s}^{2}$ & 251.119 & 1 & 251.119 & 0.84 & 0.3799 \\
\hline Total Error & 3300.61 & 11 & 300.055 & & \\
\hline Total (corr) & 125315.0 & 17 & & & $\mathbf{R}^{\mathbf{2}=\mathbf{0 . 9 7 3 6}}$ \\
\hline
\end{tabular}

Table 2. ANOVA table

The residual analysis was used to verify the adequacy of the model. A residual versus predicted value plot and normal probability plot were used to test the homogeneity of the variances and the residual normality respectively. We conclude that the model is satisfactory, and there is no need for the transformation of response variables or for additional replications for the simulation model. The second order model is then given by:

$$
\begin{aligned}
\operatorname{Cost}= & 1445.94-28.2456 * \mathrm{z}_{1}-184.254 * \mathrm{~A}+0.884791 * \mathrm{z}_{1}{ }^{2} \\
& +7.36488 * \mathrm{z}_{1} * \mathrm{~A}+235.92 * \mathrm{~A}^{2}
\end{aligned}
$$

The near-optimal control policy to be applied to the manufacturing system considered is defined by the minimum of the cost function (4) located at $z_{1}{ }^{*}=15.33, A^{*}=0.1513$ $\left(\mathrm{z}_{2}{ }^{*}=3.31\right)$, as shown in Figure $6 . \mathrm{z}_{1}{ }^{*}$ and $\mathrm{z}_{2}{ }^{*}$ define the best-multiple hedging point policy to be applied to the remanufacturing system considered. A cost value of 1215.48 results 
from this control policy. With the aforementioned optimal values of the independent factors or input parameters, the cost is minimized and the corresponding control policy is the best approximation of the optimal control one. In practice, the calculated control policy would be applied to the manufacturing system as follow:

- If surplus level of equipments is greater than 15.33 , then the repair rate is set to zero value;

- If surplus level of equipments is equal 15.33 , then, then produce at the demand rate (20 pieces of equipment / unit of time);

- If surplus level of equipments is between 2.31 and 15.33, then produce at the rate $\boldsymbol{u}_{2}$ (25 pieces of equipment / unit of time); and

- If surplus level of equipments is less than 2.31, then produce at the maximum rate $\boldsymbol{u}_{3}$ (40 pieces of equipment / unit of time).

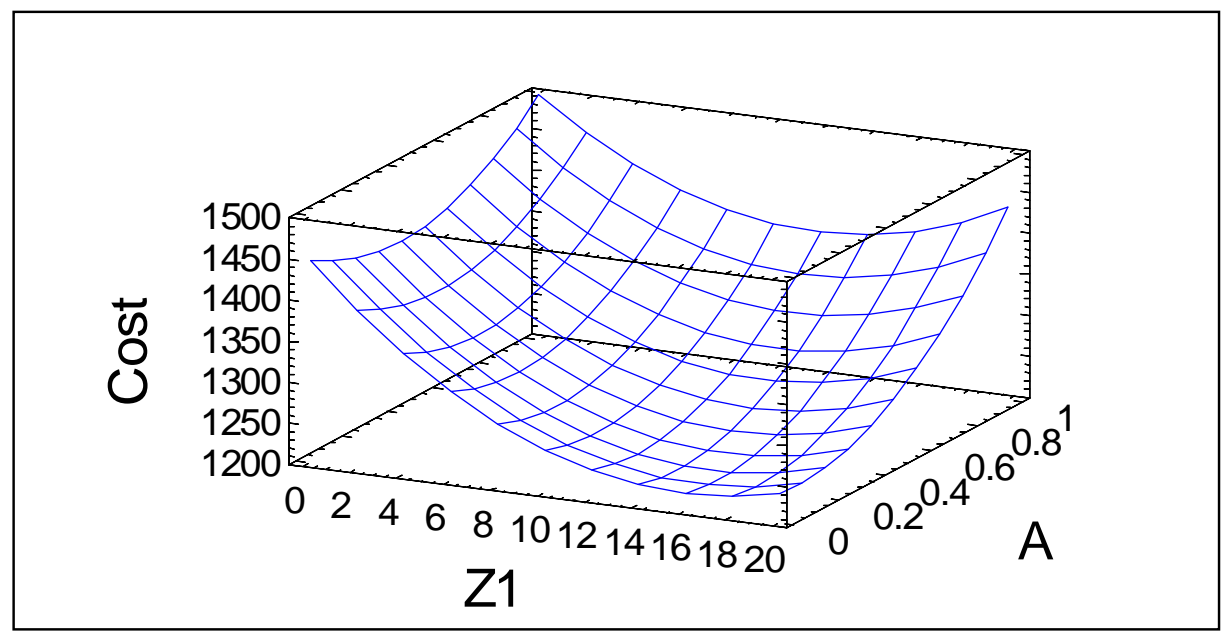

Figure 6. Estimated response surface

\subsection{Sensitivity analysis}

A set of numerical examples are considered to measure the sensitivity of the obtained control policy with respect to inventory, backlog and repair costs (i.e., $c^{+}, c^{-}, c_{1}, c_{2}$ and $c_{3}$ ). The following variations, illustrated in Table 3, are explored and compared to the basic case (experience No.1): 


\begin{tabular}{|c|c|c|c|c|c|c|c|c|c|}
\hline No. & $c^{+}$ & $c^{-}$ & $c_{1}$ & $c_{2}$ & $c_{3}$ & $\mathrm{z}_{1}{ }^{*}$ & $A^{*}\left(z_{2}^{*}\right)$ & $\mathrm{C}_{\text {MHРP }}^{*}$ § & Remark \\
\hline 1 & 10 & 100 & 20 & 40 & 100 & 15.33 & $\begin{array}{c}0.15 \\
(2.31)\end{array}$ & 1215.48 & Basic case \\
\hline 2 & 5 & 100 & 20 & 40 & 100 & 15.76 & $\begin{array}{l}0.283 \\
(4.46)\end{array}$ & 1190.28 & $\begin{array}{l}\mathrm{Z}_{1}^{*} \text { increases } \\
\mathrm{Z}_{2}{ }^{*} \text { increases }\end{array}$ \\
\hline 3 & 15 & 100 & 20 & 40 & 100 & 15.34 & $\begin{array}{c}0.05 \\
(0.76)\end{array}$ & 1231.76 & $\begin{array}{c}\mathrm{Z}_{1}{ }^{*} \text { stable } \\
\mathrm{Z}_{2}{ }^{*} \text { decreases }\end{array}$ \\
\hline 4 & 10 & 80 & 20 & 40 & 100 & 15.69 & $\begin{array}{l}0.082 \\
(1.28)\end{array}$ & 1206.06 & $\begin{array}{l}\mathrm{Z}_{1}^{*} \text { increases } \\
\mathrm{Z}_{2}{ }^{*} \text { decreases }\end{array}$ \\
\hline 5 & 10 & 150 & 20 & 40 & 100 & 15.02 & $\begin{array}{l}0.275 \\
(4.14)\end{array}$ & 1232.41 & $\begin{array}{l}\mathrm{Z}_{1}{ }^{*} \text { decreases } \\
\mathrm{Z}_{2}{ }^{*} \text { increases }\end{array}$ \\
\hline 6 & 10 & 100 & 20 & 40 & 80 & 13.89 & $\begin{array}{l}0.197 \\
(2.73)\end{array}$ & 1106.42 & $\begin{array}{l}\mathrm{Z}_{1}{ }^{*} \text { decreases } \\
\mathrm{Z}_{2}{ }^{*} \text { increases }\end{array}$ \\
\hline 7 & 10 & 100 & 20 & 40 & 120 & 16.08 & $\begin{array}{l}0.137 \\
(2.2)\end{array}$ & 1322.71 & $\begin{array}{l}\mathrm{Z}_{1}^{*} \text { increases } \\
\mathrm{Z}_{2}{ }^{*} \text { decreases }\end{array}$ \\
\hline
\end{tabular}

$\S$ the optimal incurred cost under MHPP

Table 3.Sensitivity analysis table for Multiple Hedging Point policy (MHPP)

- Decreasing $c^{+}$: this must result in a tendency to increase the stock level in order to avoid further backlog costs $\left(z_{2}{ }^{*}\right.$ increases $)$ - (experience No.2);

- Increasing $c^{+}$: this must result in a tendency to decrease the stock level in order to avoid further inventory costs $\left(\mathrm{z}_{2}{ }^{*}\right.$ decreases $)$ - (experience No.3);

- Decreasing $c^{-}$: this must result in a tendency to decrease the stock level in order to avoid further inventory costs $\left(z_{2}{ }^{*}\right.$ decreases $)$ - (experience No.4);

- Increasing $c^{-}$: this must result in a tendency to increase the stock level in order to avoid further backlog costs $\left(z_{2}{ }^{*}\right.$ increases $)$ - (experience No.5);

- Decreasing $c_{3}$ (repair cost): this must result in a tendency to increase the stock level in order to avoid further backlog costs with less increasing of repair cost $\left(z_{2}{ }^{*}\right.$ increases) - (experience No.6);

- Increasing $c_{3}$ (repair cost): this must result in a tendency to decrease the stock level in order to avoid further repair cost $\left(z_{2}{ }^{*}\right.$ decreases $)$ - (experience No.7).

The above analysis demonstrates that the results obtained are coherent and that the proposed approach is robust. 


\section{Comparison of Multiple Hedging Point Policy (MHPP) to classic Hedging Point Policy (HPP)}

In this section, we will show that the control policy presented in this paper (MHPP), which considers two thresholds related to the two accelerated repair rates, gives better results than the classic one from the literature $[10,11]$, which considers one threshold related to a unique accelerated repair rate.

The fitting of a second order polynomial model to describe the relationship between the cost and the threshold ( $\mathrm{Z}$ ) for the basic case (table 4) is then given by:

$$
\text { Cost }=1441.14-15.9448 * z+1.24658 * z^{2}
$$

We present in Table 4 the incurred optimal costs for the same sensitivity analysis input, conducted with the Hedging Point Policy (HPP). It is important to note that the results presented in Table 4 were obtained under the same conditions (simulation, experimental design and RSM), and following the same approach under which the sensitivity analysis was conducted for the MHPP (table 3). Through this analysis, It is interesting to note that $z^{*}$ does not depend on $c_{3}$, a result already mentioned in the literature. This result clearly demonstrates that the model is coherent.

\begin{tabular}{|c|c|c|c|c|c|c|c|}
\hline No. & $\boldsymbol{c}^{+}$ & $\boldsymbol{c}^{-}$ & $\boldsymbol{c}_{\mathbf{1}}$ & $\boldsymbol{c}_{\mathbf{3}}$ & $\mathbf{z}^{\boldsymbol{*}}$ & $\mathbf{C}^{\boldsymbol{*}}$ HPP $\boldsymbol{\text { Remark }}$ & Rasic case \\
\hline $\mathbf{1}$ & $\mathbf{1 0}$ & $\mathbf{1 0 0}$ & $\mathbf{2 0}$ & $\mathbf{1 0 0}$ & $\mathbf{6 . 4 0}$ & $\mathbf{1 3 9 0 . 1 5}$ & (20 \\
\hline $\mathbf{2}$ & $\mathbf{5}$ & 100 & 20 & 100 & 8.31 & 1361.94 & $z^{*}$ increases \\
\hline $\mathbf{3}$ & $\mathbf{1 5}$ & 100 & 20 & 100 & 5.11 & 1410.95 & $z^{*}$ decreases \\
\hline $\mathbf{4}$ & 10 & $\mathbf{8 0}$ & 20 & 100 & 5.50 & 1383.83 & $z^{*}$ decreases \\
\hline $\mathbf{5}$ & 10 & $\mathbf{1 5 0}$ & 20 & 100 & 7.60 & 1401.78 & $z^{*}$ increases \\
\hline $\mathbf{6}$ & 10 & 100 & 20 & $\mathbf{8 0}$ & 6.40 & 1161.44 & $z^{*}$ stable \\
\hline $\mathbf{7}$ & 10 & 100 & 20 & $\mathbf{1 2 0}$ & 6.40 & 1618.86 & $z^{*}$ stable \\
\hline
\end{tabular}

$\S$ the optimal incurred cost under HPP

Table 4. Sensitivity analysis table for Hedging Point policy (HPP)

If we compare the optimal cost values obtained by MHPP and HPP (tables 3 and 4), we notice that in all the cases $C_{M H P P}^{*}<C_{H P P}^{*}$. To confirm the numerical observation and hence 
the advantage of the proposed MHPP policy compared to that of the classic HPP, a student test has been conducted in order to compare the performance of the two policies. The confidence interval of $C_{H C P}^{*}-C_{M H C P}^{*}$ is given by (7).

$$
\begin{gathered}
\bar{C}_{H P P}^{*}-\bar{C}_{M H P P}^{*}-t_{\alpha / 2, n-1} \operatorname{see}\left(\bar{C}_{H P P}^{*}-\bar{C}_{M H P P}^{*}\right) \\
\quad \leq C_{H P P}^{*}-C_{M H P P}^{*} \leq \\
\bar{C}_{H P P}^{*}-\bar{C}_{M H P P}^{*}+t_{\alpha / 2, n-1} \operatorname{see}\left(\bar{C}_{H P P}^{*}-\bar{C}_{M H P P}^{*}\right)
\end{gathered}
$$

where:

$t_{\alpha / 2, n-1}$ is the student coefficient function of $n$ and $\alpha$, with $n$ the number of replications (set at 10) and (1- $\alpha$ ), the confidence level (set at 95\%);

$$
\begin{aligned}
& \operatorname{s.e}\left(\bar{C}_{H P P}^{*}-\bar{C}_{M H P P}^{*}\right)=\frac{S_{D}}{\sqrt{n}} \text { Standard error, } S_{D}^{2}=\frac{1}{n-1}\left(\sum_{i=1}^{n}\left(C_{H P P i}^{*}-C_{M H P P}^{*}\right)^{2}-n\left(\bar{C}_{H P P}^{*}-\bar{C}_{M H P P}^{*}\right)^{2}\right) ; \\
& \bar{C}_{H C P}^{*} \text { the average optimal cost incurred under HPP; and } \\
& \bar{C}_{M H C P}^{*} \text { the average optimal cost incurred under MHPP. }
\end{aligned}
$$

The two configurations under study (HPP and MHPP) were simulated with their optimal design parameters. The incurred cost difference $\left(C_{H P P}^{*}-C_{M H P P}^{*}\right)$ confidence interval obtained is presented in Table 5.

\begin{tabular}{|c|c|c|c|c|c|c|c|}
\hline Case & $\mathbf{1}$ & $\mathbf{2}$ & $\mathbf{3}$ & $\mathbf{4}$ & $\mathbf{5}$ & $\mathbf{6}$ & $\mathbf{7}$ \\
\hline Lower bound & 156.04 & 162.04 & 146.52 & 153.95 & 157.84 & 45.16 & 269.16 \\
\hline Upper bound & 157.07 & 162.84 & 147.82 & 155.01 & 158.93 & 46.00 & 270.51 \\
\hline
\end{tabular}

Table 5. Incurred cost difference confidence interval (95\%) for cases 1 to 7

It has been shown that in all cases, it can be concluded that $C_{H C P}^{*}-C_{M H C P}^{*}>0$ at the $95 \%$ confidence level. Consequently, the MHPP gives the lower optimal cost, and furthermore, it appears that the MHPP is better than the HPP, and can be used to better approximate the optimal control policy of the remanufacturing system. 


\section{Conclusion}

In this paper, we studied the multiple repair rate control problem of remanufacturing systems and solved the problem in the case one product type. Based on control theory, a near-optimal control policy was proposed. This policy, called multiple hedging point policy (MHPP), is described by two thresholds related to the two accelerated repair rates. To determine the parameters of the control policy, and hence, to achieve a close approximation of the optimal repair policy, an experimental approach based on design of experiment, simulation modeling and response surface methodology has been presented. The proposed approach shows that the optimal cost incurred under the developed control policy is lower than that incurred under the classical hedging point policy (HPP) and should be used for the control of remanufacturing systems.

\section{References}

[1] Guide, V.D., Jayarman, V., Srivastava, R., and Benton, W.C., Supply-Chain management for Recoverable Manufacturing Systems, Interfaces, 30(3), 125-142, 2000.

[2] Cox, J.F., Blacstone, J.H., and Spencer, M.S., APICS Dictionnary, Eigth Edition,American Production and Inventory Control Society Inc., VA, USA, 1995.

[3] Pellerin, R., Modèle d'ordonnancement dynamique de projets de réfection, Ph.D. thesis, École Polytechnique de Montréal, 1997.

[4] Gharbi, A., Girard, J., Pellerin, R. and Villeneuve, L., Bombardier turned to simulation to validate the CF-18 maintenance program, INTERFACES, 27(6), 22-34, 1997.

[5] Fleischmann, M., Bloemof-Ruwaard, J.M., Dekker, R. Van der Lann, E., Van Nunen, J.A.E.E., and VAN WASSENHOVE, L.N., Quantitative models for reverse logistics: A review, European journal of Operational Research, 103, 1-17, 1997.

[6] Mahadevan, B., Pyke, D.F., and Fleischmann, M., Periodic review, push inventory policies for remanufacturing, European Journal of Operational Research, 151, 536-551, 2003.

[7] Van der Laan, E., The effects of remanufacturing on inventory control, Doctoral dissertation, Erasmus University, School of management, Rotterdam, the Netherlands, 1997.

[8] Gharbi, A., Pellerin, R. et Villeneuve, L., A New Constraint Based Approach for Overhaul Project Scheduling with Work Space Constraints, International Journal of Industrial Engineering, Special Issue on Project Management, 6(2),123-131, 1999. 
[9] Guide, V.D., Srivastava, R., and Krause, M., Product scheduling complexity ans scheduling of operations in recoverable manufacturing, Internation Journal of production research, 10(2), 3179-3199, 1997.

[10] Akella, R. and Kumar, P. R., Optimal control of production rate in a failure-prone manufacturing system. IEEE Transactions on Automatic Control, AC-31, 116-126, 1986.

[11] Bielecki, T. and Kumar, P. R., Optimality of Zero-Inventory Policies for Unreliable Manufacturing Systems, Operations Research, 36, 532-541, 1988.

[12] Sharifnia, A., Production Control of a Manufacturing System with Multiple Machine States. IEEE Transactions, 33 (7), 620-625, 1988.

[13] Kenné, J. P. and Gharbi, A., Experimental design in production and maintenance control problem of a single machine, single product manufacturing system. International Journal of Production Research, 37(3), 621-637, 1999.

[14] Gharbi, A. and Kenné, J. P., Production and preventive maintenance rates control for a manufacturing system: an experimental design approach. International Journal of Production Economics, 65(3), 275-287, 2000.

[15] Gharbi, A. and Kenné, J. P., Optimal production control problem in stochastic multiple-product multiple-machine manufacturing systems. IIE Transactions, 35, 941-952, 2003.

[16] Pritsker, A. A. B. and O'Reilly, J. J., Simulation with Visual SLAM and Awesim, John Wiley \& Sons, 1999.

[17] Montgomery, D. C., Design and analysis of experiments, $5^{\text {th }}$ edn, John Wiley \& Sons, 2001.

[18] Law, A. M. and Kelton, W. D., Simulation modeling and analysis, $3^{\text {rd }}$ edition, McGraw-Hill, 2000.

[19] Kenné, J.P., Boukas, E.K. and Gharbi, A., Control of Production and Corrective Maintenance Rates in a Multiple-Machine, Multiple-Product Manufacturing System. Mathematical and Computer Modelling, 38, 351-365, 2003. 